Psychosis

\title{
Reconsidering the association between psychosis and suicide: a suicidal drive hypothesis
}

Jamie Murphy, Mark Shevlin, Philip Hyland, Mogens Christoffersen, Ask Elklit \& Richard Bentall

To cite this article: Jamie Murphy, Mark Shevlin, Philip Hyland, Mogens Christoffersen, Ask Elklit \& Richard Bentall (2018) Reconsidering the association between psychosis and suicide: a suicidal drive hypothesis, Psychosis, 10:4, 286-297, DOI: 10.1080/17522439.2018.1522541

To link to this article: https://doi.org/10.1080/17522439.2018.1522541

册Published online: 18 Oct 2018.

Submit your article to this journal $₫$

Llll Article views: 244

Q View related articles $₫$

View Crossmark data 


\title{
Reconsidering the association between psychosis and suicide: a suicidal drive hypothesis
}

\author{
Jamie Murphy (D) ${ }^{a}$, Mark Shevlin (iD) ${ }^{a}$, Philip Hyland (iD ${ }^{b}$, Mogens Christoffersen ${ }^{c}$, Ask Elklit ${ }^{d}$ \\ and Richard Bentalle \\ aschool of Psychology, Ulster University, Derry, Northern Ireland; bepartment of Psychology, National College of \\ Ireland, Dublin, Republic of Ireland; 'Danish National Centre for Social Research, Copenhagen, Denmark; Institute \\ of Psychology, National Centre of Psychotraumatology, University of Southern Denmark, Odense, Denmark; \\ eDepartment of Psychology, University of Sheffield, Sheffield, United Kingdom
}

\begin{abstract}
Suicidal ideation/behaviour (SIB) and psychosis are highly associated phenomena. We propose that psychosis, for some, may be consequential to SIB. More specifically we hypothesise that psychosis may serve to externalise internally generated and self-directed threat among those experiencing SIB. Using prospective data from a Danish population cohort, we first sought to test the temporal occurrence of suicidal behaviour and psychotic disorder. Next, using cross-sectional epidemiological survey data (UK), we sought to demonstrate that psychotic experiences (PEs) were more commonly reported by those who experienced $\mathrm{SIB}$ and that the strength of the association varied according to (i) SIB recency and (ii) severity. Chi-square comparison tests on the Danish data revealed that suicidal behaviour was statistically more likely to precede $(41.4 \%)$ rather than follow psychotic disorder (20.7\%). Regression analyses of the UK data indicated that individuals who thought about suicide in their lifetime were up to eight times more likely to experience specific PEs while those who thought about and attempted suicide in their lifetime and in the year of assessment were up to 48 times more likely to experience PEs, compared to SIB free members of the population. The findings provide preliminary support for a novel suicidal drive hypothesis for psychosis.
\end{abstract}

\section{ARTICLE HISTORY}

Received 16 June 2018

Accepted 8 September 2018

\section{KEYWORDS}

Suicidal ideation/behaviour; psychosis; threat;

epidemiology;

hallucinations; paranoia

\section{Introduction}

The incidence of suicidal ideation and behaviour (SIB) among individuals experiencing psychosis has been well documented (DeVylder, Lukens, Link, \& Lieberman, 2015; Radomsky, Haas, Mann, \& Sweeney, 1999). Evidence suggests that SIB is highly prevalent in samples with diagnosed psychotic disorders (Harkavy-Friedman, 2015; Palmer, Pankratz, \& Bostwick, 2005) and in clinically high-risk (CHR) and ultrahigh-risk (UHR) populations (DeVylder, Oh \& Ben-David et al. 2012; Hutton, Bowe, Parker \& Forde, 2011). In the general population SIB has also been shown to be highly prevalent among those who report PEs (Koyanagi, Stickley, \& Haro, 2015; Taylor, Hutton, \& Wood, 2015). Recent meta-analysis findings also show that individuals with schizophrenia spectrum psychosis and a history of suicidal ideation are over 6 times more likely to die by suicide (Chapman, Mullin, \& Ryan et al. 2015). Where associations between both phenomena have been investigated prospectively, only unidirectional analyses have been employed to date and SIB has always been modelled as the outcome variable (Fisher, Caspi \& Poulton et al. 2013; Kelleher, Corcoran \& Keeley et al 2013). Moreover, researchers have considered a 
wide array of factors in attempts to explain SIB among those experiencing psychosis e.g. fear of mental disintegration, depression, hopelessness, auditory hallucinations and substance misuse (Haw, Hawton, Sutton, Sinclair, \& Deeks, 2005; Hor \& Taylor, 2010).

To date, however, no known research has considered the possibility that psychosis may be consequential to SIB. While psychosis $\rightarrow$ SIB directionality certainly seems intuitively plausible, it may also be plausible to suggest that psychosis, for some, may be consequential to SIB. Such a proposal may be considered if psychosis is framed within a context of threat responsivity, i.e. responsivity to internally generated and self-directed threat.

\section{Threat response}

Threat response has been widely investigated in the research literature. Multiple theoretical models have attempted to describe the mechanisms and processes that are involved in relation to physiological and psychological reactions to perceived attack, or threat to survival (e.g. Cisler, Bacon, \&Williams, 2009; Ehlers et al., 2002; Elwood, Hahn, Olatunji, \& Williams, 2009; Foe et al., 1999). Many of these models articulate threat responsivity in terms of survival, defence and adaptation (e.g. Fox, Oler, Tromp, Fudge, \& Kalin, 2015; Schauer \& Elbert, 2015), and most, if not all, focus on threat that occurs externally to the individual (e.g. assault, accident, war, sexual victimisation, torture, neglect, etc.). Common features of threat responsivity include physical reactions e.g. coughing, vomiting, sweating, etc., and those that are psychological e.g. avoidance, submission, dissociation, "flight"/"arrested flight," etc. (e.g. Schauer \& Elbert, 2015) and each seems to characterise defensive reactions that attempt to distance or protect the individual from the immediate source of threat or danger (e.g. Wisco et al., 2015). SIB however poses an altogether unique form of threat to survival in that it is internally generated and selfdirected. While responsivity to this form of threat may also require defensive action and may necessitate some form of distancing or protection from the source of threat (in this case, the "self"), no known research has considered or explored threat responsivity in this context.

Given how grave and particularly how pervasive SIB can be therefore, and given the likely futility of psychological responses that are known to protect against external threats, those experiencing SIB may bolster defence, and in turn optimise survival by attributing their internal threat to sources other than, and external to themselves. Psychosis in the context of SIB to this end therefore, like other evolved defensive threat responses, may help to sustain life in the midst of the most severe, and otherwise inescapable forms of threat to life.

\section{Psychosis as a potential SIB threat response}

PEs, particularly positive PEs, are commonly characterised by threat related content and "externalisation" (i.e. PEs are often experienced as external to or separate from the individual). For example, paranoia and persecutory delusions often include beliefs about personal safety, impending danger and the malevolent intentionality of others to cause harm, injury or death (Bentall, Kinderman, \& Kaney, 1994; Freeman, 2007). Auditory verbal hallucinations (AVHs) also often contain and are characterised by extreme negative and threatening commentaries, often by one or more voices, which have often been known to instruct or command individuals to engage in suicidal or self-injurious behaviour (HarkavyFriedman, 2015). Moreover, passivity experiences and delusions of control, whereby individuals believe that their mind or body is under the influence or control of some kind of external force or agency are also often high in threat related content while experiences such as thought insertion and broadcasting/ diffusion, seem to reflect attributions of internal conflict/distress to external agents/sources (Frith, 2012). These beliefs and experiences, often held with great conviction, are also often highly resistant to contradictory evidence by others and are maintained despite their perceived implausibility (Garety, Freeman \& Jolley et al. 2005). If defensive reactions ultimately serve to distance or protect an individual from a source of threat or danger, distance and protection from the "self" in the context of SIB is possibly more likely to be achieved by some psychological process of threat externalisation (i.e. 
attribution of self-threat to sources other than, and external to the self). Heightened PE prevalence among those experiencing SIB may reflect such a process.

\section{SIB before psychosis}

While no known research has explored this hypothesis recent evidence does seem to show that SIB may be common prior to psychosis. For example, in two samples of individuals at risk of psychosis a high prevalence of suicidal ideation prior to clinical assessment was observed (72.0-76.9\%) (Hui, Morcillo \& Russo et al 2013; Hutton, Bowe, \& Parker et al, 2011). Similarly, Welsh and Tiffin (2013) reported that $30 \%$ of a sample of adolescents at an "at-risk mental state" for psychosis had attempted suicide in the past six months. Moreover, a recent study investigating SIB prior to first presentation of psychosis and during a 3-year follow-up in a sample of 397 first episode psychosis patients found that the greatest suicide risk was found during the month before and 2 months after first contact with psychiatric services (i.e. "early" attempts) (Ayesa-Arriola, Alcaraz, \& Hernández et al. 2015). Indeed, 15$26 \%$ of patients have attempted suicide at least once by their first contact while an additional $2-11 \%$ make another attempt during the first year of treatment (Agerbo, Nordentoft \& Mortensen, 2002; Addington, Williams, Young, \& Addington, 2004; Verdoux, Liraud \& Gonzales et al. 2001). Recently, Granö, Karjalainen, Suominen, and Roine (2011) found that adolescents at heightened risk of psychosis had significantly higher scores of suicidal ideation compared with other help-seeking adolescents, suggesting that the association may be present already before service utilisation. Furthermore, while monitoring CHR patients enrolled in an early intervention programme for psychosis, Preti, Meneghelli, Pisano, and Cocchi (2009) found that as psychosis symptom severity decreased, SIB decreased also. Notably however, each of these researchers have adhered to more traditional perspectives regarding psychosis $\rightarrow$ suicide directionality.

To initiate empirical testing of a suicidal drive hypothesis therefore the current study sought to (i) demonstrate that suicidal behaviour was more likely to precede psychotic disorder, (ii) demonstrate that PEs would be more commonly reported by those who experienced SIB, and (iii) demonstrate that the strength of the association between PEs and SIB would vary according to both SIB recency and severity. It was proposed that if psychosis was responsive to internally generated and self-directed threat then it would not only be preceded by suicidal behaviour but that PEs would be more strongly associated with SIB at more extreme levels and where SIB was most recent and/or sustained. These preliminary hypotheses were formulated to offer a necessary first investigatory step before exploration of the broader proposed threat response aspects of the hypothesis could be considered.

\section{Materials and methods}

\section{Samples}

Two separate data resources were utilised to test the proposed hypotheses. All data handling, analyses and dissemination of findings were conducted in accordance with the ethical guidelines set out by the Danish (the National Centre for Social Research; https://en.sfi.dk/) and UK (UK Data Service; https://www.ukdataservice.ac.uk/) data custodians.

\section{Danish data}

To investigate the temporal occurrence of suicidal behaviour and psychotic disorder, prospective cohort data from Denmark were accessed. A complete cohort of all individuals born in Denmark in 1984 ( $N=27,840$ males and 26,618 females followed from birth in 1984 to early adulthood in 2005) was sourced. Using the Danish Psychiatric Nationwide Case Register and the National Patient Register, annual hospital admissions data for suicidal behaviour (hospitalisation for self-harm or suicidal behaviour) and psychosis (psychotic disorder diagnosis) were targeted specifically (see Shevlin, et al., 2016; 
Thygesen, Daasnes, Thaulow, \& Brønnum-Hansen, 2011) for full details on structure and access of Danish health and social registry data).

\section{Measures}

\section{Psychotic disorder and suicidal behaviour}

To attain a suitable measure of psychosis, annually recorded status denoting presence of schizophrenia, schizotypal and delusional disorders (ICD-10 F20-F29) was selected from the Psychiatric Case Register. In Denmark, every time a person is treated in a psychiatric hospital or department they receive an ICD-10 (previously ICD-8/9) diagnosis code, made by a psychiatrist, which is recorded on the appropriate register. Diagnosis status (has received diagnosis/no diagnosis) was identifiable annually for all individuals in the cohort therefore it was possible to establish in which year(s) psychotic disorder was present, if at all, for the entire sample. Overall, from 1984 to 2005 $406(0.7 \%)$ individuals from the cohort had received a psychotic disorder diagnosis (average age of first diagnosis $=18.14$ years; $S D=3.37$ ).

To attain a suitable measure of suicidal behaviour, data denoting self-harm and suicide attempts were sourced from the Danish Psychiatric Nationwide Case Register and the National Patient Register. The definition of suicide attempts included behaviour that conformed to the following three conditions: (i) suicide attempts that led to hospitalisation, (ii) assessment of trauma being an act of self-mutilation according to the international statistical classification of injuries when discharged from hospital, and (iii) trauma included in a specified list of traumas traditionally connected with suicide attempts: e.g. cutting in wrist (carpus), firearm wounds, hanging, selfpoisoning with drugs, pesticide, cleaning fluids, alcohol, or carbon monoxide. Also included was intentional self-harm according to hospital admissions in a psychiatric ward. Once again suicidal behaviour status was identifiable annually therefore it was possible to establish in which year(s) suicidal behaviour was present, if at all, for the entire sample. Overall, from 1984 to 20051,034 (1.8\%) individuals from the cohort had a hospital/psychiatric record denoting self-harm and/or suicide attempts (average age of first hospitalisation $=15.13$ years; SD $=5.95$ ).

\section{UK data}

To explore prevalence estimates of PEs and SIB items in relation to high-risk age categories for SIB and to investigate whether the strength of the association between PEs and SIB would vary according to SIB recency and severity, data from two UK-based epidemiological surveys were accessed. Specifically, data were taken from the British Psychiatric Morbidity Survey (BPMS) and the Adult Psychiatric Morbidity Survey (APMS). The primary aim of these epidemiological surveys was to estimate the prevalence and correlates of mental health problems among adults aged 16 and over living in private households in the United Kingdom (UK). A two-phase approach was used in both surveys. The first phase interviews included structured assessments serving diagnostic criteria and screening instruments for a range of mental disorders, as well as questions on topics such as general health, service use, risk factors and demographics. The second-phase interviews were carried out by clinically trained research interviewers. Using the small users' postcode address file (PAF) the National Centre for Social Research (NatCen) adopted a multi-stage stratified probability sampling design. One adult aged 16 years or over was selected for interview within each household. Details of both survey methodologies are available (McManus, Meltzer, Brugha, Bebbington, \& Jenkins, 2009; Singleton, Bumpstead, O'Brien, Lee, \& Meltzer, 2001). In the BPMS Interviews were successfully conducted with 8580 adults (3852 males and 4728 females; mean age 45.36 (SD = 15.61) while in the APMS Interviews were successfully conducted with 7403 adults (3197 males and 4206 females; mean age $51.12(S D=18.59)$ years). 
While the Danish data were limited to clinical records of psychotic disorder and hospital treatment for SIB, analyses conducted on the UK data were specifically designed to investigate sub-clinical PE. Importantly, individuals experiencing subclinical PE in the general population were less likely to have been exposed to factors that have been associated with SIB and PE in a clinical context. E.g. hopelessness, stigma and social exclusion often attached to receiving treatment for psychotic disorder (Tarrier, Khan, Cater, \& Picken, 2007), and the distress commonly associated with admission to hospital for many who are diagnosed with a psychotic disorder (Morrison, Bowe, Larkin, \& Nothard, 1999) were recognised as potentially important factors that were unlikely to be applicable to the entire sample. Therefore, those individuals who were diagnosed with a psychotic disorder were omitted from the analyses (the overall weighted prevalence of psychosis was; BPMS $=0.4 \%(N=32)$; APMS $=0.4 \%$ $(N=29)$. The remaining sample sizes were; BPMS $N=8548$; APMS $N=7266$.

\section{Measures}

\section{Sib}

A positive response to suicidal thoughts or attempts was followed up with a question on whether this last occurred in the past week, the past year or during the respondent's lifetime before the past year. Given the low endorsement of suicidal attempts "in the past week" in both samples (BPMS $N=2$; APMS $N=0$ ) data denoting SIB in the past year and the past week were aggregated to produce variables denoting SIB in the past year. To acquire a combined measure of change in recency and severity of SIB the variables in each dataset were recoded to produce five categories of SIB recency and severity (see Table 1 ).

\section{Pes}

In both UK surveys, the psychosis screening questionnaire (PSQ; Bebbington \& Nayani, 1995) was administered to assess psychotic symptoms within the past year. The PSQ consisted of five main questions enquiring about mania, thought insertion, paranoia, strange experiences and hallucinations, (P1 to P5), their subsidiary question(s) ( $a$ and or b) and sections to record verbatim descriptions of the symptoms described. For the purposes of the current study, analysis was based solely on selected subsidiary questions of the PSQ items to attempt to capture clinically relevant psychotic experiences within the sample. The current analyses focussed specifically on PSQ items 2 through 5 due to the

Table 1. UK data SIB and PSQ item selection.

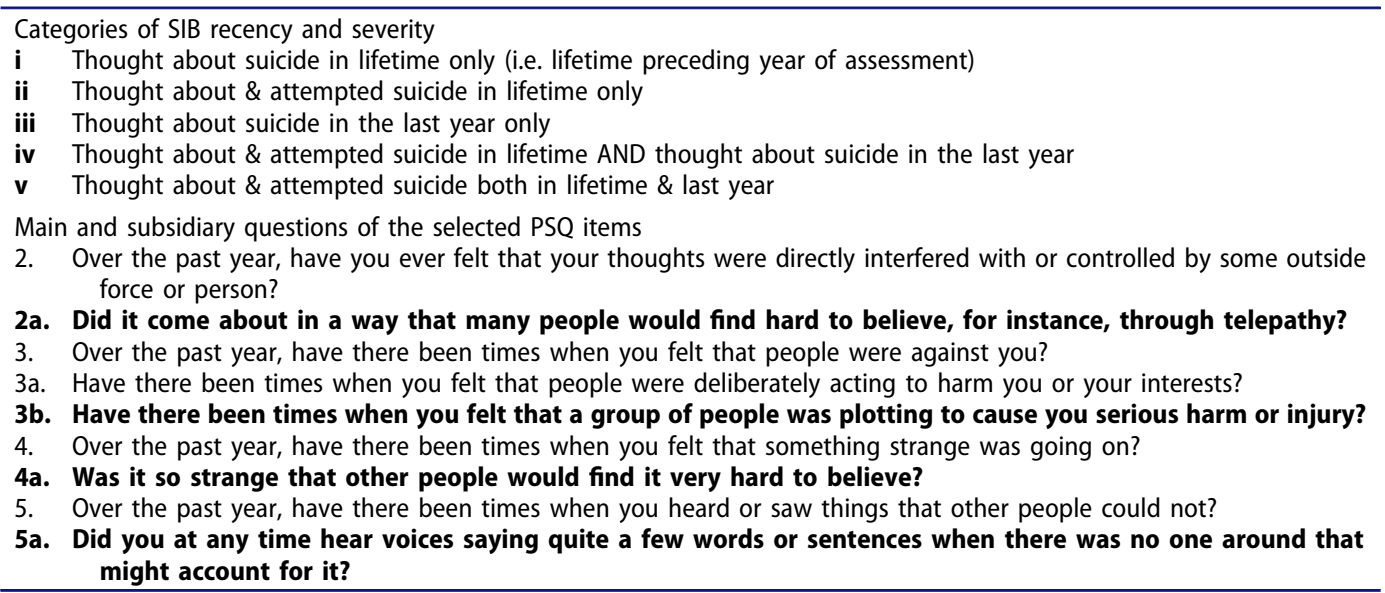

PSQ = Psychosis screening questionnaire (for PSQ items the analysis relevant questions are in bold). 
inflated endorsement of the mania probe in both surveys (BPMS $=$ APMS $=$ PSQ1 $=52 \%$ endorsement). This item ("Over the past year, have there been times when you felt very happy indeed without a break for days on end?") was considered less reliable as an accurate screen for psychosis given that over half of both samples endorsed the probe, whereas no more than $18 \%$ of the samples endorsed either of the remaining four probe items. Responses to each of the selected questions were coded $1=$ item endorsed; $0=$ item rejected. An "unsure" response to any of the four items was recoded and treated as missing data. The main and subsidiary questions of the selected PSQ items were (see Table 1: analysis relevant questions in bold):

\section{Covariate selection}

A range of PE covariates were also selected, re-coded and statistically controlled for in the analyses of the UK data. These included respondent: sex, age, ethnicity (white/non-white), education (possessed qualifications/no qualifications), employment status (employed/unemployed), living status (lived alone/co-habited), trauma history (experienced sexual abuse, homelessness or violence in the home/no trauma), alcohol dependence (present/absent), cannabis use (used at least once/never used), and any neurotic disorder (present/absent).

\section{Results}

\section{Danish data analysis of suicidal behaviour/self-harm and psychotic disorder}

To begin, prospective cohort data from the Danish health and social registry were sourced to investigate the temporal occurrence of suicidal behaviour/self-harm and psychotic disorder where both phenomena co-occurred. In total, $406(0.7 \%)$ individuals from the cohort had received a psychotic disorder diagnosis in their lifetime and 1,034 (1.8\%) had a hospital/psychiatric record denoting suicidal behaviour/self-harm. Overall, $82(0.1 \%)$ individuals had a record of both psychotic disorder diagnosis and treatment for suicidal behaviour/self-harm. Among those with dual status (occurrence of both suicidal behaviour/self-harm and psychotic disorder) 31 (37.8\%) received hospital treatment for suicidal behaviour/self-harm and were diagnosed with a psychotic disorder in the same year; 34 (41.4\%) were hospitalised for suicidal behaviour/self-harm in the year(s) prior to psychotic disorder diagnosis; and 17 (20.7\%) were diagnosed with a psychotic disorder in the year(s) prior to hospitalisation for suicidal behaviour/self-harm $\left(x^{2}=6.02(\mathrm{df}=2) p=0.049\right)$. Notably, most individuals $(38 \%)$ who were treated for suicidal behaviour/self-harm prior to treatment for psychosis were treated in the year before psychotic disorder diagnosis and most individuals who were diagnosed with a psychotic disorder prior to treatment for suicidal behaviour/self-harm were diagnosed in the year before hospitalisation for suicidal behaviour/self-harm (82.3\%). Proportionally however the analysis showed that suicidal behaviour/self-harm either preceded or co-occurred with psychotic disorder in $79 \%$ of dual status cases.

\section{UK data analysis of SIB and PE}

Next, analyses were then employed to test whether PE prevalence increased in relation to SIB recency and severity. In the BPMS and the APMS PE prevalence among those who did not report SIB was below $1 \%$ for all PE items except item 4 ("strange experiences"; BPMS $=2.1 \%$; APMS $=1.8 \%$ ). Overall, the prevalence of strange experiences (PSQ 4) was higher for each of the SIB recency-severity categories compared to the other PE items. Generally, PE prevalence increased steadily in relation to both the recency and the severity of SIB. Among those who both thought about and attempted suicide in both their lifetime preceding the year of assessment and during the year of assessment, $17.47 \%$ on average reported a PE. Cross-tabulations between PE items and SIB recency and severity categories are presented in Table 2. 
Table 2. Associations between PEs and SIB items in the BPMS \& APMS.

\begin{tabular}{|c|c|c|c|c|c|c|c|c|}
\hline \multirow[b]{3}{*}{ SIB (recency \& severity) } & \multirow{2}{*}{\multicolumn{2}{|c|}{$\begin{array}{c}\text { PSQ2 } \\
\text { Thought control } \\
\text { Yes N (\%) }\end{array}$}} & \multirow{2}{*}{\multicolumn{2}{|c|}{$\begin{array}{c}\text { PSQ3 } \\
\text { Paranoia } \\
\text { Yes N (\%) }\end{array}$}} & \multirow{2}{*}{\multicolumn{2}{|c|}{$\begin{array}{c}\text { PSQ4 } \\
\text { Strange experiences } \\
\text { Yes N (\%) }\end{array}$}} & \multirow{2}{*}{\multicolumn{2}{|c|}{$\begin{array}{c}\text { PSQ5 } \\
\text { Hallucinations } \\
\text { Yes N (\%) }\end{array}$}} \\
\hline & & & & & & & & \\
\hline & BPMS & APMS & BPMS & APMS & BPMS & APMS & BPMS & APMS \\
\hline None & $48(0.7)$ & $32(0.5)$ & $63(0.9)$ & $50(0.8)$ & $152(2.1)$ & $110(1.8)$ & $28(0.4)$ & $11(0.2)$ \\
\hline Thought lifetime-only & $15(2.1)$ & $7(1.5)$ & $22(3.1)$ & $16(3.3)$ & $29(4.1)$ & $31(6.5)$ & $8(1.1)$ & $5(1.0)$ \\
\hline $\begin{array}{l}\text { Thought \& attempt lifetime } \\
\text { only }\end{array}$ & $11(3.6)$ & $6(2.4)$ & $18(5.9)$ & $14(5.7)$ & $28(9.1)$ & $22(9.0)$ & $11(3.6)$ & $8(3.2)$ \\
\hline Thought lifetime \& last year & $7(3.0)$ & $11(5.2)$ & $20(8.4)$ & $14(6.5)$ & $29(12.3)$ & $25(11.8)$ & $8(3.4)$ & $5(2.3)$ \\
\hline $\begin{array}{l}\text { Thought \& attempt lifetime \& } \\
\text { thought last year }\end{array}$ & $6(10.5)$ & $3(7.0)$ & $9(15.8)$ & $5(11.6)$ & $16(28.6)$ & $6(14.6)$ & $5(8.6)$ & $3(7.0)$ \\
\hline $\begin{array}{l}\text { Thought \& attempt lifetime \& } \\
\text { last year }\end{array}$ & $5(10.6)$ & $3(8.6)$ & $8(17.4)$ & $9(25.7)$ & $18(38.3)$ & $9(25.7)$ & $5(10.6)$ & $1(2.9)$ \\
\hline$x^{2} p$ & $132.41^{* * *}$ & $107.79^{* * *}$ & $277.78^{* * *}$ & $267.59^{* * *}$ & $431.00^{* * *}$ & $233.68^{* * *}$ & $175.81^{* * *}$ & $117.76^{* * *}$ \\
\hline
\end{tabular}

To test whether the association between PEs and SIB would vary according to both the recency of the ideation and the severity of the ideation, while controlling for a range of variables known to be associated with $\mathrm{PE}$, a multivariate logistic regression model was specified and estimated. Mplus 5.21 (Muthén \& Muthén, 2007) was used to estimate the model parameters using robust full information maximum likelihood. This method allowed parameters to be estimated using all available information and has been found to be superior to alternative methods such as listwise deletion (Enders, 2001; Schafer \& Graham, 2002). Regarding covariate effects, both regression models (BPMS \& APMS) were largely consistent with one another.

\section{SIB recency-severity and PE}

Regarding SIB recency and severity, overall in both regression models (Tables 3 and 4), the likelihood of experiencing psychosis was lowest for those characterised by the least severe (thought only) and most distant (lifetime before year of assessment) SIB. Conversely, the likelihood of experiencing psychosis in the year of assessment was highest for those who reported sustained SIB (i.e. thought about and attempted suicide in lifetime both during and before the year of assessment). Generally, odds ratios for PE were larger in the APMS analysis. Regarding individual PEs, reported by those with the most severe and recent $\mathrm{SIB}$, hallucinations were most likely in the BPMS (adjusted $\mathrm{OR}=7.48 ; 95 \% \mathrm{Cl}=2.31-24.27$ ), whereas paranoia was most likely in the APMS (adjusted OR $=16.88 ; 95 \% \mathrm{Cl}=6.61-43.08$ ). In both models also, the odds of reporting hallucinations were higher in cases where SIB included a suicide attempt, i.e. regardless of general SIB recency. The unadjusted odds ratios indicated that PEs, on average, were significantly more likely to be reported in all SIB recency-severity categories (Average unadjusted ORs from least severe and most distant SIB to most recent and severe SIB, across both surveys $=$ Thought Lifetime Only $=3.82$, Thought $\&$ Attempt Lifetime Only $=8.35$, Thought Life Time \& Last Year $=8.52$, Thought $\&$ Attempt Lifetime a Thought Last Year $=23.10$, Thought $\&$ Attempt Lifetime \& Last Year $=24.74)$.

\section{Discussion}

\section{Does suicidal behaviour/self-harm precede psychotic disorder?}

The findings from the Danish prospective data suggested that, where both suicidal behaviour/selfharm and psychotic disorder co-occurred, suicidal behaviour/self-harm was more likely to precede psychotic disorder. Specifically, Danish registry records showed that $41 \%$ of those who had a history of both suicidal behaviour/self-harm and psychotic disorder were hospitalised for suicidal behaviour/selfharm before psychotic disorder was diagnosed. Conversely, records showed that $21 \%$ of those with 
Table 3. Associations between PEs, PE correlates and SIB items for BPMS.

\begin{tabular}{|c|c|c|c|c|}
\hline & \multicolumn{4}{|c|}{ ORs (95\% Cls) } \\
\hline & $\begin{array}{c}\text { PSQ2 } \\
\text { Thought control }\end{array}$ & $\begin{array}{c}\text { PSQ3 } \\
\text { Paranoia }\end{array}$ & $\begin{array}{c}\text { PSQ4 } \\
\text { Strange experiences }\end{array}$ & $\begin{array}{c}\text { PSQ5 } \\
\text { Hallucinations }\end{array}$ \\
\hline \multicolumn{5}{|l|}{ Demography } \\
\hline Sex (female $55.1 \%$ ) & $1.02(0.62-1.68)$ & $0.54^{* *}(0.36-0.82)$ & $1.04(0.77-1.41)$ & $1.15(0.57-2.32)$ \\
\hline Age $(x=45.38 ; S D=15.62)$ & $1.01(0.99-1.03)$ & $1.00(0.98-1.01)$ & $0.98^{* * *}(0.97-0.99)$ & $1.00(0.98-1.03)$ \\
\hline Ethnicity (non-white 5.6\%) & $1.25(0.47-3.34)$ & $3.39^{* * *}(1.79-6.42)$ & $1.31(0.77-2.22)$ & $2.25(0.90-5.58)$ \\
\hline $\begin{array}{l}\text { Education (no qualifications } \\
28.5 \% \text { ) }\end{array}$ & $1.67(0.98-2.83)$ & $1.25(0.77-2.01)$ & $0.98(0.69-1.40)$ & $1.38(0.78-2.45)$ \\
\hline Employment (unemployed 40.9\%) & $1.26(0.75-2.14)$ & $1.10(0.71-1.71)$ & $1.43^{*}(1.04-1.97)$ & $0.85(0.45-1.65)$ \\
\hline Living alone (alone $22.4 \%$ ) & $1.31(0.80-2.15)$ & $0.95(0.62-1.46)$ & $1.25(0.92-1.69)$ & $1.02(0.56-1.87)$ \\
\hline \multicolumn{5}{|l|}{ Environmental correlates } \\
\hline Trauma (present 12.5\%) & $2.73^{* *}(1.50-4.96)$ & $3.77^{* * *}(2.41-5.89)$ & $1.73^{* *}(1.21-2.48)$ & $2.14^{*}(1.10-4.15)$ \\
\hline Alcohol (problem 24.1\%) & $1.28(0.69-2.36)$ & $0.74(0.49-1.12)$ & $0.79(0.58-1.08)$ & $1.47(0.72-2.99)$ \\
\hline Cannabis (used 21.9\%) & $1.40(0.71-2.76)$ & $1.34(0.83-2.16)$ & $1.17(0.84-1.62)$ & $1.33(0.59-3.01)$ \\
\hline \multicolumn{5}{|l|}{ Clinical correlates } \\
\hline $\begin{array}{l}\text { Any neurotic disorder (present } \\
17.4 \%)\end{array}$ & $1.70(0.91-3.19)$ & $2.98^{* * *}(1.89-4.69)$ & $3.41 * * *(2.45-4.76)$ & $3.17^{* * *}(1.70-5.89)$ \\
\hline \multicolumn{5}{|l|}{ SIB (recency \& severity) } \\
\hline \multirow[t]{2}{*}{ Thought lifetime only } & $2.38^{*}(1.23-4.62)$ & $1.77(0.95-3.30)$ & $1.09(0.67-1.80)$ & $1.99(0.70-5.64)$ \\
\hline & $3.30 * * *$ & $3.07 * * *$ & $1.99 * *$ & $3.06 *$ \\
\hline \multirow[t]{2}{*}{ Thought \& attempt lifetime only } & $3.23^{* *}(1.39-7.51)$ & $2.81^{* *}(1.41-5.60)$ & $1.85^{*}(1.04-3.27)$ & $3.84^{* *}(1.42-10.39)$ \\
\hline & $6.82 * * *$ & $7.83 * * *$ & $4.67^{* * *}$ & $8.99 * * *$ \\
\hline \multirow[t]{2}{*}{ Thought life time \& last year } & $2.43(0.89-6.63)$ & $4.34^{* * *}(2.11-8.93)$ & $2.40 * *(1.42-4.08)$ & $3.25^{*}(1.28-8.26)$ \\
\hline & $4.17^{* *}$ & $10.06^{* * *}$ & $6.10 * * *$ & $6.99 * * *$ \\
\hline $\begin{array}{l}\text { Thought \& attempt lifetime \& } \\
\text { thought last year }\end{array}$ & $\begin{array}{c}3.22 *(1.06-9.83) \\
14.28 * * *\end{array}$ & $\begin{array}{c}5.16^{* *}(1.95-13.66) \\
\mathbf{2 5 . 8 1 * * *}\end{array}$ & $\begin{array}{c}4.71^{* * *}(2.13-10.42) \\
21.72^{* * *}\end{array}$ & $\begin{array}{c}6.39^{* *}(1.92-21.30) \\
\mathbf{2 5 . 0 8} \text { ( }^{* *}\end{array}$ \\
\hline Thought \& attempt lifetime \& last & $4.47^{*}(1.11-18.05)$ & $4.62^{* *}(1.72-12.42)$ & $5.64^{* * *}(2.45-12.97)$ & $7.48^{* *}(2.31-24.27)$ \\
\hline year & $14.43 * * *$ & $18.78 * * *$ & $22.93^{* * *}$ & $21.16^{* * *}$ \\
\hline
\end{tabular}

Unadjusted odds ratios are in bold; ${ }^{*}=p<0.05 ;{ }^{* *}=p<0.01 ;{ }^{* *}=p<0.001$

"dual status" were diagnosed with a psychotic disorder before they received hospital attention for suicidal behaviour/self-harm. These prospective findings, while offering tentative support for the proposed hypotheses, must also however be considered in light of some notable limitations. First, it was not possible to establish which experience came first among those whose records showed suicidal behaviour/self-harm and psychotic disorder in the same year. Given that data were available on an annual basis only, temporal ordering of both phenomena within the same year was not possible. Second, suicidal behaviour/self-harm and psychotic disorder status in the Danish data were entirely restricted to cases that were clinically and publically recorded. The Danish cohort data therefore did not recognise suicidal ideation, which generally precedes behaviour. Importantly also, the Danish data were likely to be inclusive of non-suicidal traumas, injuries and self-harm without suicidal intent. Likewise, it did not assess PE which typically precedes psychotic disorder. Therefore, the fact that hospitalisation for suicidal behaviour/self-harm was more likely to occur before hospitalisation for psychotic disorder does not necessarily mean that suicidal ideation occurred before PE. This analysis therefore is only representative of the more extreme manifestations of these phenomena.

\section{Does PE vary in relation to SIB?}

The findings from the analyses of both UK survey datasets revealed that (i) that PE prevalence seemed to increase in relation to both the recency and the severity of SIB and (ii) that PEs were statistically more likely to be associated with more recent and more severe SIB. that have favoured a PE $\rightarrow$ SIB framework. For example, this was not the first analysis of PE and SIB using the UK data. Recently Koyanagi et al. (2015) found that individual PEs in the APMS were significantly associated with suicidal thoughts (ORs 3.22 to 4.20 ) and suicide attempts (ORs 3.95 to 10.23). In addition, a greater number of PEs was associated with higher odds for suicidal ideation and suicide attempt. 
Table 4. Associations between PEs, PE correlates and SIB items for APMS.

\begin{tabular}{|c|c|c|c|c|}
\hline & \multicolumn{4}{|c|}{ ORs (95\% Cls) } \\
\hline & $\begin{array}{c}\text { PSQ2 } \\
\text { Thought control }\end{array}$ & $\begin{array}{c}\text { PSQ3 } \\
\text { Paranoia }\end{array}$ & $\begin{array}{c}\text { PSQ4 } \\
\text { Strange experiences }\end{array}$ & $\begin{array}{c}\text { PSQ5 } \\
\text { Hallucinations }\end{array}$ \\
\hline \multicolumn{5}{|l|}{ Demography } \\
\hline Sex (female $56.5 \%$ ) & $0.86(0.47-1.58)$ & $0.46^{* *}(0.27-0.78)$ & $0.69 *(0.49-0.99)$ & $0.58(0.26-1.32)$ \\
\hline Age $(x=51.17 ; S D=18.59)$ & $1.02(0.99-1.04)$ & $0.97^{* * *}(0.96-0.99)$ & $0.99 *(0.97-1.00)$ & $0.99(0.96-1.02)$ \\
\hline Ethnicity (non-white 7.3\%) & $2.80 *(1.09-7.22)$ & $4.52^{* * *}(2.43-8.42)$ & $0.76(0.43-1.34)$ & $4.21(0.51-34.58)$ \\
\hline $\begin{array}{l}\text { Education (no qualifications } \\
28.4 \% \text { ) }\end{array}$ & $0.98(0.48-2.00)$ & $1.42(0.78-2.57)$ & $0.73(0.49-1.10)$ & $1.26(0.37-4.29)$ \\
\hline $\begin{array}{l}\text { Employment (unemployed } \\
48.1 \% \text { ) }\end{array}$ & $1.33(0.72-2.45)$ & $0.98(0.60-1.61)$ & $0.74(0.52-1.06)$ & $0.57(0.25-1.27)$ \\
\hline Living alone (alone 28\%) & $1.55(0.87-2.74)$ & $1.52(0.88-2.62)$ & $1.20(0.85-1.69)$ & $0.84(0.37-1.92)$ \\
\hline \multicolumn{5}{|l|}{ Environmental correlates } \\
\hline Trauma (present 13.8\%) & $1.74(0.80-3.80)$ & $2.97^{* * *}(1.72-5.13)$ & $1.71 * *(1.15-2.54)$ & $1.15(0.44-3.03)$ \\
\hline Alcohol (problem 21.6\%) & $1.48(0.79-2.79)$ & $1.67(0.99-2.80)$ & $1.38(0.95-2.01)$ & $1.04(0.39-2.77)$ \\
\hline Cannabis (used 19.2\%) & $1.17(0.57-2.37)$ & $0.70(0.41-1.19)$ & $0.79(0.52-1.20)$ & $0.69(0.21-2.27)$ \\
\hline \multicolumn{5}{|l|}{ Clinical correlates } \\
\hline $\begin{array}{l}\text { Any neurotic disorder (present } \\
16.4 \% \text { ) }\end{array}$ & $1.99(0.97-4.08)$ & $2.80^{* * *}(1.62-4.83)$ & $4.10^{* * *}(2.77-6.07)$ & $3.54(0.91-13.84)$ \\
\hline \multicolumn{5}{|l|}{ Suicidality (recency \& severity) } \\
\hline Thought lifetime only & $\begin{array}{c}2.24(0.80-6.27) \\
2.66^{*}\end{array}$ & $\begin{array}{c}2.79 * *(1.34-5.83) \\
4.09 * * *\end{array}$ & $\begin{array}{c}2.75^{* * *}(1.65-4.59) \\
\mathbf{4 . 3 8 * * *}\end{array}$ & $\begin{array}{c}6.27^{* *}(1.58-24.77) \\
7.99 * * *\end{array}$ \\
\hline Thought \& attempt lifetime only & $\begin{array}{c}2.92^{*}(1.00-8.53) \\
4.32^{* *}\end{array}$ & $\begin{array}{c}2.78^{*}(1.18-6.56) \\
6.10 * * *\end{array}$ & $\begin{array}{c}2.58^{* *}(1.31-5.09) \\
\mathbf{5 . 9 3}^{* * *}\end{array}$ & $\begin{array}{c}11.70^{* *}(2.72-50.26) \\
\mathbf{2 2 . 1 5 * * *}\end{array}$ \\
\hline Thought life time \& last year & $\begin{array}{c}5.64^{* *}(2.09-15.20) \\
\mathbf{8 . 1 6 * * *}\end{array}$ & $\begin{array}{c}3.53^{* *}(1.57-7.92) \\
7.79 * * *\end{array}$ & $\begin{array}{c}3.67^{* * *}(2.01-6.70) \\
9.88^{* * *}\end{array}$ & $\begin{array}{c}7.52^{* *}(1.67-33.79) \\
15.07^{* * *}\end{array}$ \\
\hline $\begin{array}{l}\text { Thought \& attempt lifetime \& } \\
\text { thought last year }\end{array}$ & $\begin{array}{c}6.17^{*}(1.05-36.38) \\
\mathbf{1 8 . 5 8}^{* * *}\end{array}$ & $\begin{array}{c}9.91^{* *}(2.42-40.67) \\
\mathbf{2 4 . 9 7 * * *}\end{array}$ & $\begin{array}{c}2.75(0.90-8.43) \\
12.46 * * *\end{array}$ & $\begin{array}{c}13.61^{*}(1.85-100.14) \\
\mathbf{4 1 . 9 0 * * *}\end{array}$ \\
\hline $\begin{array}{l}\text { Thought \& attempt lifetime \& last } \\
\text { year }\end{array}$ & $\begin{array}{c}5.71^{*}(1.23-26.38) \\
\mathbf{1 0 . 7 2}^{* * *}\end{array}$ & $\begin{array}{c}16.88^{* * *}(6.61-43.08) \\
\mathbf{4 7 . 6 4 ^ { * * * }}\end{array}$ & $\begin{array}{c}5.32^{* * *}(2.17-13.05) \\
\mathbf{2 0 . 6 1 * * *}\end{array}$ & $\begin{array}{c}4.41(0.45-43.60) \\
\mathbf{4 1 . 6 3 * * *}\end{array}$ \\
\hline
\end{tabular}

Unadjusted odds ratios are in bold; ${ }^{*}=p<0.05 ;{ }^{* *}=p<0.01 ;{ }^{* *}=p<0.001$

Koyanagi's findings also complimented and seemed consistent with other "sub threshold PE-SIB" studies based on Australian (Taylor et al., 2015) and US (Saha et al., 2011) population samples. These studies, however, did not consider an inverse relationship between these phenomena. The findings from the current set of analyses therefore suggest that SIB $\rightarrow$ PE effects lie in the same range as effects reported in $\mathrm{PE} \rightarrow \mathrm{SIB}$ studies, and as such merit equal consideration.

A number of analytic limitations must also be considered in relation to the UK findings. First, while PE was anchored to the year of assessment in both UK surveys it was not possible to determine whether PE was present before SIB in the years preceding assessment. Prospective data analysis will be required to offer a more robust test however to date, as mentioned, findings from extant research, modelling SIB as an outcome variable, have adopted a similar analytic strategy using similar data (Koyanagi et al., 2015; Saha et al., 2011; Taylor et al., 2015). Second, while every effort was made in the UK analyses to measure "'true'" subclinical psychotic experiences, the measurement of psychosis-like symptoms can be confounded by numerous factors such as respondents' misunderstanding the nature of the questions or normalising the experiences (Wittchen \& Kessler, 2010).

\section{Extant evidence suggesting SIB $\rightarrow$ psychosis directionality}

While such findings are a necessary entry point for the proposed hypothesis they are in themselves however only a crude suggestion of causality. Similar findings using alternative prospective data will be required before the hypothesis can be justifiably explored further. At present, however, the hypothesis is potentially supported by findings elsewhere in the psychosis research literature. Most notably, the proposed hypothesis seems consistent with much of the extant cognitive literature surrounding PEs. For example, at a phenomenological level, PEs, particularly positive PEs, are commonly characterised by negative beliefs about the self, and threat-related content. Cognitive 
theorists have hypothesised that these experiences occur when intrusive and distressing mental events are experienced as ego-dystonic and therefore externalised (Morrison, Bowe, Larkin, Nothard, 1999). Paranoia and persecutory delusions, for example, become more prominent when the activation of negative self-schemas leads to the expectation of harm from others (Fowler, Hodgekins \& Garety, et al. 2012). Moreover, it is believed that AVHs result from the misattribution of self-directed inner speech to an external source (Harkavy-Friedman et al., 2003). There is evidence that these experiences may emerge from distressing intrusive thoughts (e.g. negative self-evaluation; suicidal ideation) (e.g. Langdon, Jones, Connaughton, \& Fernyhough, 2009). Moreover, research on source monitoring has consistently shown that auditory hallucinations are associated with an externalising bias for negative internal events (Morrison \& Baker, 2000); in the context of the current hypothesis, we argue that the inner speech that is externalised may be suicide-related.

\section{Conclusion}

Given the novelty of the hypothesis, the authors wish to be cautious about proposing potential clinical implications at this time. However, if psychosis is shown to be sometimes consequential to internally generated, self-directed and inescapable threat to the self, then some initial implications are worth considering. First, SIB should be explored as a potential risk factor that might be included in prospective assessment tools to be used with, for example, high-risk groups. Second, clinical interventions with high-risk and first episode psychosis samples might pay particular attention to episodes of suicidal ideation in patients' histories.

It is also important, however, to recognise that, for some, these phenomena may be entirely separate but arise due to shared risk factors. Both phenomena are also, regardless of co-occurrence or order, likely to represent maladaptive attempts to deal with unwanted/distressing thoughts, emotions, or situations. Clinical interventions therefore will likely need to focus on helping individuals to recognise the context and history of their experiences, beliefs and behaviours but more importantly to help them to recover or attain a sense of worth, value and belonging.

In conclusion, many others before have introduced/entertained concepts such as e.g. "splitting", "projection" and "dissociation" in attempts to explain the "strange" phenomenology of psychosis (e.g. Klein; Feigenbaum; Bleuler). In 1911, Bleuler in fact referred to the "suicidal drive" as "the most serious of schizophrenic symptoms". While our proposed hypothesis does not necessarily recognise SIB as a symptom of psychosis, it does recognise SIB as a potential driver of psychosis and in turn, suggests that psychosis may be, in part, a response to one of the most intolerable threats that an individual can experience.

\section{Disclosure statement}

No potential conflict of interest was reported by the authors.

\section{ORCID}

Jamie Murphy (D) http://orcid.org/0000-0003-1821-0025

Mark Shevlin (D) http://orcid.org/0000-0001-6262-5223

Philip Hyland (iD) http://orcid.org/0000-0002-9574-7128

\section{References}

Addington, J., Williams, J., Young, J., \& Addington, D. (2004). Suicidal behaviour in early psychosis. Acta Psychiatrica Scandinavica, 109, 116-120.

Agerbo, E., Nordentoft, M., \& Mortensen, P. B. (2002). Familial, psychiatric, and socioeconomic risk factors for suicide in young people: Nested case-control study. British Medical Journal, 325, 74. 
Ayesa-Arriola, R., Alcaraz, E. G., Hernández, B. V., Pérez-lglesias, R., Moríñigo, J. D. L., Duta, R., ... Crespo-Facorro, B. (2015). Suicidal behaviour in first-episode non-affective psychosis: Specific risk periods and stage-related factors. European Neuropsychopharmacology. doi:10.1016/j.euroneuro.2015.09.008

Bebbington, P., \& Nayani, T. (1995). The psychosis screening questionnaire. International Journal of Methods in Psychiatric Research, 5, 11-19.

Bentall, R. P., Kinderman, P., \& Kaney, S. (1994). The self, attributional processes and abnormal beliefs: Towards a model of persecutory delusions. Behaviour Research and Therapy, 32, 331-341.

Bleuler, E. (1911). (1950). Dementia Praecox or the group of Schizophrenias (Trans. J. Zinkin). New York, NY: International Universities Press.

Chapman, C. L., Mullin, K., Ryan, C. J., Kuffel, A., Nielssen, O., \& Large, M. M. (2015). Meta-analysis of the association between suicidal ideation and later suicide among patients with either a schizophrenia spectrum psychosis or a mood disorder. Acta Psychiatrica Scandinavica, 131, 162-173.

Cisler, J. M., Bacon, A. K., \& Williams, N. L. (2009). Phenomenological characteristics of attentional biases towards threat: A critical review. Cognitive Therapy and Research, 33, 221-234.

DeVylder, J. E., Lukens, E. P., Link, B. G., \& Lieberman, J. A. (2015). Suicidal ideation and suicide attempts among adults with psychotic experiences: Data from the collaborative psychiatric epidemiology surveys. JAMA Psychiatry (Chicago, III.), 72, 219-225.

DeVylder, J. E., Oh, A. J., Ben-David, S., Azimov, N., Harkavy-Friedman, J. M., \& Corcoran, C. M. (2012). Obsessive compulsive symptoms in individuals at clinical risk for psychosis: Association with depressive symptoms and suicidal ideation. Schizophrenia Research, 140, 110-113.

Ehlers, A., Hackmann, A., Steil, R., Clohessy, S., Wenninger, K., \& Winter, H. (2002). The nature of intrusive memories after trauma: The warning signal hypothesis. Behavior Research and Therapy, 40, 995-1002.

Elwood, L. S., Hahn, K. S., Olatunji, B. O., \& Williams, N. L. (2009). Cognitive vulnerabilities to the development of PTSD: A review of four vulnerabilities and the proposal of an integrative vulnerability model. Clinical Psychology Review, 29, 87-100.

Enders, C. K. (2001). The performance of the full information maximum likelihood estimator in multiple regression models with missing data. Educational and Psychological Measurement, 5, 713-740.

Fisher, H. L., Caspi, A., Poulton, R., Meier, M. H., Houts, R., Harrington, H., .. Moffitt, T. E. (2013). Specificity of childhood psychotic symptoms for predicting schizophrenia by 38 years of age: A birth cohort study. Psychological Medicine, 43, 2077-2086.

Foa, E. B., Ehlers, A., Clark, D. M., Tolin, D. F., \& Orsillo, S. M. (1999). The posttraumatic cognitions inventory (PTCI): development and validation. Psychological Assessment, 11, 303.

Fowler, D., Hodgekins, J., Garety, P. A., Freeman, D., Kuipers, E., Dunn, G., .. Bebbington, P. E. (2012). Negative cognition, depressed mood, and paranoia: A longitudinal pathway analysis using structural equation modeling. Schizophrenia Bulletin, 38, 1063-1073.

Fox, A. S., Oler, J. A., Tromp, D. P., Fudge, J. L., \& Kalin, N. H. (2015). Extending the amygdala in theories of threat processing. Trends in Neurosciences, 38, 319-329.

Freeman, D. (2007). Suspicious minds: The psychology of persecutory delusions. Clinical Psychological Review, 27, $425-457$.

Frith, C. (2012). Explaining delusions of control: the comparator model 20years on. Conscious Cognition, 21, 52-54.

Garety, P. A., Freeman, D., Jolley, S., Dunn, G., Bebbington, P. E., Fowler, D. G., .. Dudley, R. (2005). Reasoning, emotions, and delusional conviction in psychosis. Journal of Abnormal Psychology, 114, 373.

Granö, N., Karjalainen, M., Suominen, K., \& Roine, M. (2011). Poor functioning ability is associated with high risk of developing psychosis in adolescents. Nordic Journal of Psychiatry, 65, 16-21.

Harkavy-Friedman, J. M. (2015). Suicide risk and prevention in patients with schizophrenia. Suicidologi, $14,2$.

Harkavy-Friedman, J. M., Kimhy, D., Nelson, E. A., Venarde, D. F., Malaspina, D., \& Mann, J. J. (2003). Suicide attempts in schizophrenia: The role of command auditory hallucinations for suicide. Journal of Clinical Psychiatry, 64, 871-874.

Haw, C., Hawton, K., Sutton, L., Sinclair, J., \& Deeks, J. J. (2005). Schizophrenia and deliberate self-harm: A systematic review of risk factors. Suicide and Life- Threatening Behaviour, 35, 50-62.

Hor, K., \& Taylor, M. (2010). Suicide and schizophrenia: A systematic review of rates and risk factors. Journal of Psychopharmacology, 24, 81-90.

Hui, C., Morcillo, C., Russo, D. A., Stochl, J., Shelley, G. F., Painter, M., ... Perez, J. (2013). Psychiatric morbidity, functioning and quality of life in young people at clinical high risk for psychosis. Schizophrenia Research, 148, 175-180.

Hutton, P., Bowe, S., Parker, S., \& Ford, S. (2011). Prevalence of suicide risk factors in people at ultra-high risk of developing psychosis: A service audit. Early Intervention in Psychiatry, 5, 375-380.

Kelleher, I., Corcoran, P., Keeley, H., Wigman, J. T., Devlin, N., Ramsay, H., .. Wasserman, D. (2013). Psychotic symptoms and population risk for suicide attempt: A prospective cohort study. JAMA Psychiatry (Chicago, III.), 70, $940-948$.

Koyanagi, A., Stickley, A., \& Haro, J. M. (2015). Subclinical psychosis and suicidal behavior in England: findings from the 2007 adult psychiatric morbidity survey. Schizophrenia Research, 168, 62-67.

Langdon, R., Jones, S. R., Connaughton, E., \& Fernyhough, C. (2009). The phenomenology of inner speech: Comparison of schizophrenia patients with auditory verbal hallucinations and healthy controls. Psychological Medicine, 39(04), 655-663. 
McManus, S, Meltzer, H, Brugha, T. S, Bebbington, P. E, \& Jenkins, R. (2009). Adult psychiatric morbidity in England, 2007: Results of a household survey. UK Data Archive Study Number 6379. The NHS Information Centre for Health and Social Care

Morrison, A. P., \& Baker, C. A. (2000). Intrusive thoughts and auditory hallucinations: A comparative study of intrusions in psychosis. Behaviour Research and Therapy, 38(11), 1097-1106.

Morrison, A. P., Bowe, S. B., Larkin, W., \& Nothard, S. (1999). The psychological impact of psychiatric admission: Some preliminary findings. [Report]. Journal of Nervous Mental Disorders, 187, 250-253.

Muthén, L., \& Muthén, B. (2007). Mplus User Guide. Los Angeles, CA: Statmodel.

Palmer, B. A., Pankratz, S., \& Bostwick, J. M. (2005). The life time risk of suicide in schizophrenia: Are examination. JAMA Psychiatry (Chicago, III.), 62, 247-253.

Preti, A., Meneghelli, A., Pisano, A., \& Cocchi, A. (2009). Risk of suicide and suicidal ideation in psychosis: Results from an Italian multi-modal pilot program on early intervention in psychosis. Schizophrenia Research, 113, 145-150.

Radomsky, E. D., Haas, G. L., Mann, J. J., \& Sweeney, J. A. (1999). Suicidal behavior in patients with schizophrenia and other psychotic disorders. American Journal of Psychiatry, 156, 1590-1595.

Saha, S., Scott, J. G., Johnston, A. K., Slade, T. N., Varghese, D., Carter, G. L., \& McGrath, J. J. (2011). The association between delusional-like experiences and suicidal thoughts and behaviour. Schizophrenia Research, 132, $197-202$.

Schafer, J. L., \& Graham, J. W. (2002). Missing data: Our view of the state of the art. Psychological Methods, 7, $147-177$.

Schauer, M., \& Elbert, T. (2015). Dissociation following traumatic stress. Zeitschrift für Psychologie, 218, $109-127$.

Shevlin, M., McElroy, E., Christoffersen, M. N., Elklit, A., Hyland, P., \& Murphy, J. (2016). Social, familial and psychological risk factors for psychosis: A birth cohort study using the Danish Registry System. Psychosis, 8(2), 95-105.

Singleton, N., Bumpstead, R., O'Brien, M., Lee, A., \& Meltzer, H. (2001). Psychiatric morbidity among adults living in private households. London: TSO.

Tarrier, N., Khan, S., Cater, J., \& Picken, A. (2007). The subjective consequences of suffering a first episode psychosis: Trauma and suicide behaviour. Social Psychiatry and Psychiatric Epidemiology, 42, 29-35.

Taylor, P. J., Hutton, P., \& Wood, L. (2015). Are people at risk of psychosis also at risk of suicide and self-harm? A systematic review and meta-analysis. Psychological Medicine, 45, 911-926.

Thygesen, L. C., Daasnes, C., Thaulow, I., \& Brønnum-Hansen, H. (2011). Introduction to Danish (nationwide) registers on health and social issues: Structure, access, legislation, and archiving. Scandinavian Journal of Public Health, 39, 12-16.

Verdoux, H., Liraud, F., Gonzales, B., Assens, F., Abalan, F., \& Van Os, J. (2001). Predictors and outcome characteristics associated with suicidal behaviour in early psychosis: A two-year follow-up of first-admitted subjects. Acta Psychiatrica Scandinavica, 103, 347-354.

Welsh, P., \& Tiffin, P. A. (2013). The 'at-risk mental state' for psychosis in adolescents: Clinical presentation, transition and remission. Child Psychiatry and Human Development,45, 90-98.

Wisco, B. E., Marx, B. P., Sloan, D. M., Gorman, K. R., Kulish, A. L., \& Pineles, S. L. (2015). Self-distancing from trauma memories reduces physiological but not subjective emotional reactivity among veterans with posttraumatic stress disorder. Clinical Psychological Science, 3(6), 956-963.

Wittchen, H.-U., \& Kessler, R. C. (2010). Modifications of the CIDI in the national comorbidity survey: the development of the UMCIDI: NCS working paper \#2. 1994. http://www.hcp.med.harvard.edu/ncs/ftpdir/um-cidi.pdf. Accessed May 7, 2010. 